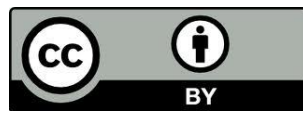

\title{
O CONTO DE VÖLSI: ASPECTOS DO PAGANISMO NA ERA VIKING
}

The tale of Volsi: aspects of the heathenism in Viking age

\author{
Johnni Langer \\ Doutorado em História, \\ Pós-Doutorado em História Medieval, \\ Professor adjunto Ciências das Religiões Universidade Federal da Paraíba, UFPB
}

RESUMO: O artigo investiga o conto islandês Völsa páttr, datado do século XV, contendo uma narrativa sobre um suposto culto fálico numa comunidade rural da Escandinávia durante o final da Era Viking. Partindo dos pressupostos da Nova História Cultural e de uma discussão historiográfica, realizamos a pesquisa procurando relacionar a religiosidade desta região com problemáticas da cultura medieval.

Palavras-chave: Era Viking; Paganismo; Idade Média; História das religiões.

ABSTRACT: The article investigates the Icelandic tale Völsa páttr dating from the fifteenth century, containing a narrative of a supposed phallic cult in a rural community in Scandinavia during the late Viking Age. Based on the assumptions of the New Cultural History and a historiographical discussion, conducted research seeking to relate the religiosity of this region with problems of medieval culture.

Key words: Viking Age; Heathenism; Middle Age; History of Religions. 
Um pequeno conto do final da Idade Média revela uma surpreendente narrativa sobre a religiosidade de personagens pouco estudados, tanto na história das religiões quanto nos estudos medievais de maneira geral: os camponeses. Desde a sua publicação nos tempos modernos, o Völsa páttr vem gerando muita polêmica: constitui um caso verídico de práticas religiosas da Escandinávia da Era Viking (c. 973-1066 d.C.)? Ou seria uma invenção posterior de autores cristãos para desmoralizar o antigo paganismo? No presente estudo, pretendemos refletir sobre essa fonte através de novas abordagens, esperando alargar os debates para além dos estudos escandinavísticos, abrangendo também o fenômeno religioso em seu caráter cultural. A primeira parte do trabalho aborda questões teóricas e metodológicas, enquanto na segunda analisamos em detalhes a narrativa medieval, e na conclusão, voltamos a refletir sobre a relação entre cultura e religiosidade para o caso nórdico.

\section{Cultura e religiosidade}

Desde o Iluminismo, o fenômeno religioso ocupou o interesse dos acadêmicos, mas levaria muito tempo para que se fosse instaurada uma disciplina configurada como história das religiões. No século XVIII predominava a crença em uma essência universal do sentimento religioso, atrelada a idéia de uma natureza humana. Apesar de viajantes europeus já registrarem formas diferenciadas de crenças pelo mundo, a abordagem teológica ainda imperava plenamente (HERMANN, 2010, p. 315). A idéia do Homo religiosus foi o substrato fundamental dos estudos oitocentistas e de grande parte da fenomenologia, a exemplo de Mircea Eliade. Este último, em suas obras, procurou mais um sistema descritivo do que explicativo, buscando uma tipologia genérica das formas e práticas religiosas (CARDOSO, 2005, p. 211). A essência da religião era mais buscada do que a sua história. Ao construir seu modelo comparativo, Eliade buscava a essência dos fenômenos de crença, criando generalizações, regras ahistóricas e interpretações irracionalistas (HERMANN, 2010, p. 321).

Instaurada como disciplina no Oitocentos, a Etnologia dedicou-se a sistematizar as diferentes sociedades, sendo as crenças uma chave fundamental para a organização destas. Mas nesta época, as teorias evolucionistas, os modelos biológicos e as ideias político-sociais eurocêntricas referendavam as religiões enquanto partes de um processo de evolução espiritual. Foi com o surgimento da sociologia que o papel social das 
religiões passou a ocupar um patamar mais importante nas reflexões acadêmicas. Ainda assim, pesquisadores como Émile Durkheim buscavam as características essenciais de todas as religiões: uma explicação genérica ainda era o objetivo das investigações (HERMANN, 2010, p. 316-318).

As interpretações mais recentes questionam a existência de uma natureza humana e se preocupam muito mais com sua re-elaboração histórica. Também não se busca mais a origem dos mitos ou das crenças, objetivos comuns ao positivismo, cientificismo e ideologias oitocentistas (HERMANN, 2010, p. 323-324). A visão antropológica e histórica tem se multiplicado desde a segunda metade do século 20, enfatizando os aspectos culturais do fenômeno das crenças coletivas. Mas temos que levar em conta que se as interpretações sobre cultura se modificaram, obviamente, os enfoques culturais da religião também. Tradicionalmente, o social é pensado enquanto a totalidade das relações que os grupos mantêm entre um mesmo conjunto, enquanto a cultura seria o social visto de seus aspectos individuais: "cultura é o conjunto dos comportamentos, saberes e saber-fazer característicos de um grupo humano ou de uma sociedade" (LAPLANTINE, 1999, p. 120). Por sua vez, os estudos de aculturação levaram a uma redefinição de cultura, recebendo esta um referencial mais dinâmico e deixando de ter um caráter monolítico. Ela não existiria em estado puro, sempre igual: toda cultura estaria em permanente processo de construção, desconstrução e reconstrução, sendo a aculturação universal. Com isso não existiriam culturas puras nem mestiças, mas mistas. E essa dinâmica é construída sincronicamente, isto é, historicamente (CUCHE, 2002, p. 137-142).

A Antropologia cultural define a religião como uma crença no sobrenatural, atuando como uma força coercitiva de uma sociedade. Criam-se pessoas qualificadas para tratar esse sobrenatural, os sacerdotes e suas técnicas, e também templos e hierarquias, originando os aspectos institucionais que são característicos das religiões (TITIEV, 1979, p. 290-298). E o quanto de uniformidade teria uma religião em uma dada sociedade? Os sentimentos, sonhos, mitos, utopias, a magia, os medos passaram a ser estudados especialmente pela Nova História Cultural, originando as pesquisas de religiosidade folclórica: "a religião popular é um momento essencial da cultura popular" (FRANCO JÚNIOR, 1996, p. 33). Mas o que seria exatamente uma cultura popular? 
Existem diversas interpretações, as mais importantes giram em torno de dois referenciais: o que concebe as culturas populares como sem criatividade e marginais, e outra, que identifica nela autonomia e autenticidade. Hoje em dia, os antropólogos percebem que elas não são totalmente dependentes, nem autônomas, e sim, uma reunião de elementos originais, importados, emprestados ou inventados. Como qualquer cultura, não é homogênea, mas construída numa situação de dominação e contestação (CUCHE, 2002, p. 146-156). Uma das noções mais importantes da nova historiografia, a circularidade e o hibridismo cultural - no caso das pesquisas de Carlo Ginzburg demonstraram que crenças populares e de elite, apesar de diferentes, quando em contato realizam trocas e re-significações. Um dos grandes estereótipos religiosos modernos, o sabá (a reunião das bruxas), nasceu efetivamente do cruzamento conflituoso entre cultura folclórica e erudita durante o final da Idade Média (GINZBURG, 2001, p. 22). Desta maneira, o autor conseguiu identificar relações diacrônicas entre mitos e ritos, recusando a interpretação fenomenológica que buscava uma essência religiosa e empregando um método comparativo historiográfico (HERMANN, 2010, p. 329).

E justamente, o campo das pesquisas sobre cultura e religião popular foi onde se abriu o enfoque da história religiosa de um campo tradicional, institucional, para o estudo das sensibilidades: "os sentimentos religiosos fortemente enraizados não podem ser alcançados a não ser através de suas expressões culturais" (FRANCO JÚNIOR, 1996, p. 33). Além disso, os historiadores culturais estão adotando um conceito de religião mais amplo, que permita sair dos discursos da tradição judaico-cristã; que possibilite estudar as manifestações de crença de pessoas não filiadas a nenhuma instituição; abandono da busca de uma essência nas religiões e entender os sentimentos de crença a partir de recortes históricos; que crie condições para ir além da teologia e pensar as crenças e práticas, tanto comunitárias quanto individuais, entrando no campo das religiosidades (BELLOTTI, 2004, p. 100). Para outros, o conceito de religiosidade substitui o de "superstição", com forte carga pejorativa, e o de "religião popular", que implica em radicalismos com relação à crenças oficiais. Com isso, poderíamos ter com esse conceito três níveis de análise: a religião formal; os sentimentos, atitudes e comportamentos do religioso; as práticas e manifestações concretas (CARDOSO, 2005, p. 222-223). 
Em outro viés, podemos entender a religiosidade como um campo de articulação entre a religião, a magia e o mito - conceitos tradicionalmente opostos ou com vínculos, dependendo do enfoque teórico. A Antropologia Cultural tradicionalmente separa as crenças no sobrenatural em dois tipos básicos: naquelas realizadas em épocas específicas do ano (religiosas) das feitas em momentos de crise (mágicas). Quase sempre os ritos mágicos não possuem estrutura institucional e igrejas, mas nem sempre são realizados no ambiente domésticos ou individual (existem ritos mágicos públicos, como em épocas de guerra ou catástrofes, TITIEV, 1979, p. 307). A oposição entre essas duas formas de crenças, entre uma mais complexa, com conteúdo teológico (religião) e outra de caráter mais simples ou pré-científica (magia), também vem sendo descartada entre os pesquisadores. Na realidade, ambas se interpenetram. As duas são sistemas simbólicos e de conhecimento, de forte caráter social, mas diferenciando-se quanto ao seu exercício: a magia tende ao individual e é fonte de imoralidade, anomia, enquanto a religião tem forte conotação moral e coesão (MONTEIRO, 1986, p. 15). Quanto aos mitos, são narrativas orais e imagéticas que fundam/explicam a realidade natural por meio de sentidos culturais (MASSENZIO, 2005, p. 141); operando como modelo de comportamento, guia para o cotidiano e o transcendente, e como discurso metafórico sobre o divino, o natural e o humano (FRANCO JÚNIOR, 1996, p. 38-39).

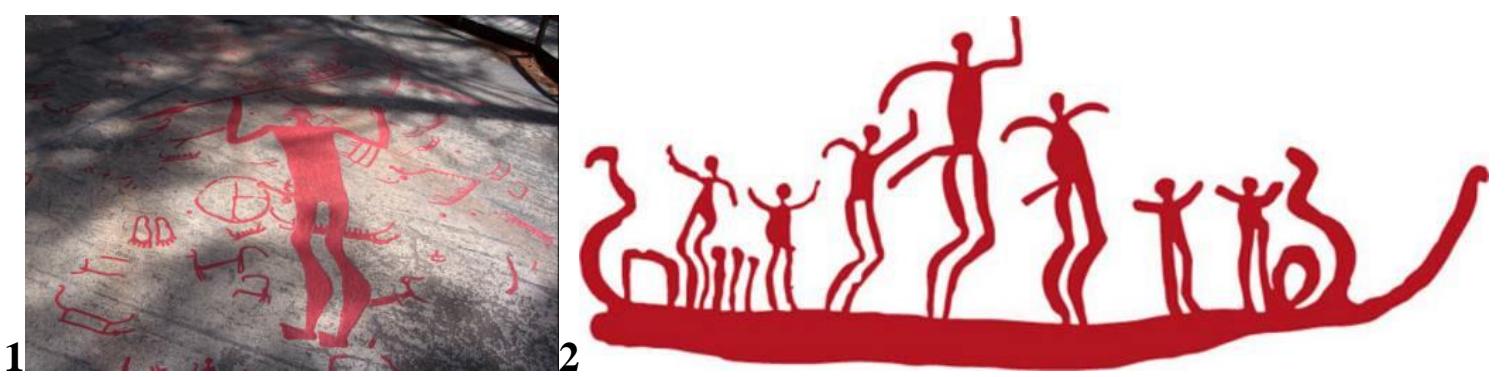

Figuras 1 e 2: Pinturas rupestres de Tanum, Bohuslän, Suécia, datadas de 1.800 a 400 a. C. Fonte: http://www.rockartscandinavia.se/ Acesso em 28 de janeiro de 2012.

Figuras masculinas com o pênis ereto, a maioria portando armamento (machados, espadas ou lanças). Algumas destas figuras estão em meio a diversos tipos de animais quadrúpedes, outros viajam em barcos (figura 2). Certas representações masculinas em posição falocêntrica possuem um tamanho descomunal em relação às figuras ao seu redor, o que pode indicar serem divindades ou seres sobrenaturais (A mais famosa tem pelo menos cinco vezes o tamanho das figuras masculinas em sua volta e porta uma grande lança em suas mãos, sendo vista como a figuração de Odin, figura 1, BOYER, 1997, p. 119). Outras figuras fálicas são duplicadas, possuindo o mesmo armamento e a mesma posição uma defronte da outra, indicando talvez algum tipo de culto. Também existem representações de casais abraçados (onde o homem está excitado e portando uma espada), tendo outra figura de guerreiro fálico portando um machado logo acima de suas cabeças - vista como uma representação do hierogamos, o casamento 
sagrado (BOYER, 1997, p. 81). Ainda segundo o mitólogo Régis Boyer, estas figuras estariam relacionadas a cultos solares e a ritos de procissão, destacando as imagens em que seres masculinos transportam em suas mãos pequenos barcos (1981, p. 60-62). Analisando todo o conjunto rupestre da Idade do Bronze de Bohuslän, podemos perceber uma grande antiguidade do culto fálico na Escandinávia, muito tempo antes da Era Viking.

Em nosso referencial, magia, religião e mito fazem parte dos mesmos sistemas de crença e cosmovisão de uma sociedade em dada época, mas podem diferir em sua visão de mundo. A diferença não está tanto em seu instrumental, na estrutura da prática, e sim no contexto de sua operacionalidade. Na Inglaterra tardo-medieval, as cerimônias católicas não possuíam a mesma devoção para todos os membros: enquanto os sacerdotes e aristocratas seguiam o missal dentro da estrutura teológica vigente, a maior parte do público, constituído por camponeses analfabetos, aguardava ansiosamente o momento da consagração da hóstia, que para eles, era um momento mágico. Após o ritual, a hóstia (que não era engolida pelos comungantes) era utilizada para operações mágicas, como cura a doentes ou proteção contra má sorte (THOMAS, 1991, p. 42). Até hoje, muitos católicos fervorosos recorrem em ambiente doméstico, a serviços de benzeções e práticas de curas mágicas (não totalmente aceitas pelos eclesiásticos e pela instituição católica), enquanto padres rezam missas pelo rádio ou TV e seus devotos bebem um copo de água, supostamente "consagrado" durante a cerimônia em seus lares (GERRIERO, 2003, p. 26). Com isso, percebemos que no medievo:

1 - Os indivíduos de uma mesma cultura compartilhavam dos mesmos mitos (na Era Viking, a mitologia escandinava; no cristianismo medieval, essencialmente as narrativas de origem bíblica), mas nem sempre com conotações, interpretações e sentidos idênticos;

2 - As pessoas de uma mesma cultura compartem genericamente da mesma religião, mas selecionam as categorias míticas conforme sua categoria social ou a rede de relações sociais da qual fazem parte (na Era Viking, existiam cultos específicos para deuses da fertilidade entre os camponeses - os Vanes, enquanto a elite perpetuava mais os ritos odínicos. Mas em momentos sazonais, existiam celebrações que envolviam todos os membros da sociedade);

3 - Os integrantes da mesma cultura partilham de crenças mágicas, mas elas podem se diferir em sua estrutura pelo viés social (No mundo cristão, ocorria a magia 
popular, de origem folclórica, e a erudita, que mesclava a tradição oriental e eclesiástica entre os letrados. Ambas podiam utilizar a Bíblia como repertório mágico).

A relação entre apreensão cultural e social da religiosidade é uma perspectiva que necessita sempre ser equalizada: o conceito de cultura pode ser muito útil para objetos materiais, normas de comportamento e processos de pensamento, enquanto sociedade se distingue das outras por apresentar configurações específicas em uma rede fechada de relações sociais (CARDOSO, 2005, p. 278). Tanto a religião quanto a magia utilizam o mito como instrumento de controle do sobrenatural, com variações ao nível social $\mathrm{Na}$ religião pagã nórdica, as divindades podem ser celebradas em oferendas e sacrifícios públicos e sazonais (como Odin, nos cultos escandinavos, neste caso enfatizando sua auto-imolação na árvore cósmica de Yggdrasill, LANGER, 2005, p. 7), mas também invocadas em rituais privados, a exemplo da utilização de deuses para aplacar doenças em inscrições de amuletos (a placa rúnica de Ribe conclama Odin para combater a dor e anões maléficos, MACLEOD, 2006, p. 25). Neste caso, as narrativas míticas são selecionadas conforme o contexto operacional dos praticantes. Estelas com cenas mitológicas foram muito empregadas para demarcar sepulturas de guerreiros na ilha de Gotland. Sendo membros da aristocracia nórdica, os temas que mais aparecem representados nestes monumentos foram vinculados ao triunfo marcial do morto chegando ao palácio do Valhala, onde reina Odin (LANGER, 2003, p. 93-129). Enquanto as práticas funerárias são terrenos típicos da religião, por sua vez os rituais envolvendo algum tipo de auxílio são da magia. Aqui a seleção da narrativa oral mitológica pode envolver outros aspectos da mesma deidade - nos rituais de seiðr, Odin surge relacionado à magia da deusa Freyja, em seus aspectos xamânico e psicopombo (LANGER, 2010, p. 3). 


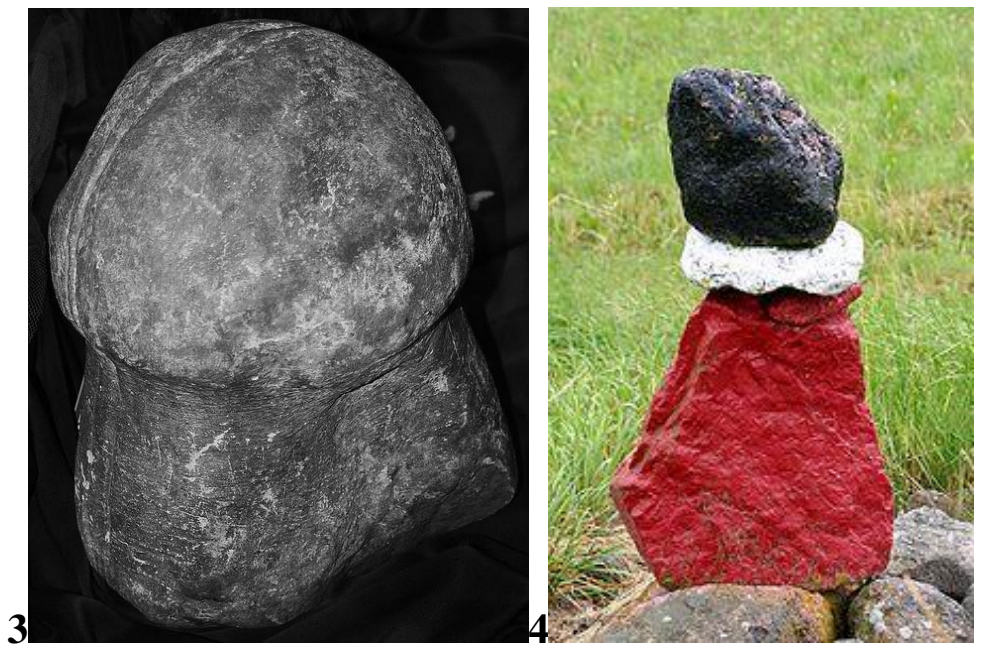

Figura 3: Rocha fálica da Nouega, século III-VI d. C., Historisk Museum Oslo. Fonte: http://www.flickr.com/photos/28772513@N07/3566337017/ Acesso em 05 de janeiro de 2012.

Figura 4: Rödsten (Pedra vermelha), Östergötland, Suécia. Fonte: http://www.panoramio.com/photo/21173751 Acesso em 05 de janeiro de 2012. Monumento cujo nome foi registrado pela primeira vez em 1360, sugerindo uma longa tradição num papel associado a ritos de fertilidade. Acredita-se que desgraças podem acontecer se a pedra não for regularmente pintada das cores vermelho, preto e branco. Esse folclore pode ter sido derivado de antigas práticas sacrificiais que pintavam a rocha com sangue (SANMARK, 2004, p. 165).

O conceito de religiosidade pode tornar esse quadro muito mais instrumental aos historiadores, possibilitando perceber os espaços específicos de cada prática, sem perder de vista a dinâmica e o contexto de relação entre elas. Com a cristianização da Escandinávia (no século XI), os relatos míticos desaparecem dos cultos públicos, substituídos pela tradição judaico-cristã, mas não da oralidade e do mundo privado. $\mathrm{O}$ folclore dará sobrevivência às narrativas dos antigos deuses, preservados em vários tipos de literatura no período cristão (séculos XIII a XV), e atuando ininterruptamente no universo da magia mesmo com o desabrochar dos tempos modernos (século XVI, LANGER, 2009a, p. 66-90). ${ }^{1}$ Seja com operações mágicas dos tempos vikings que ainda sobrevivem no mundo camponês, seja com ritos mesclados ao universo ocultista de origem oriental, o mito adapta-se aos novos tempos.

A religiosidade deve ser sempre pensada como um sistema simbólico extremamente dinâmico, produto constante de hibridismos e resignificações culturais,

\footnotetext{
${ }^{1} \mathrm{O}$ surpreendente ressurgimento de um culto individual ao deus Odin em Estocolmo, que levou Ragvald Odinskarl para a inquisição em 1484 (MITCHELL, 2009, p. 263-286).
} 
de preservação ou inovação de elementos autóctones e estrangeiros. Sem apelarmos para uma ideia de natureza humana universal, inconsciente e anistórica (seja o Homo symbolicus, o Homo religiosus ou os arquétipos do inconsciente coletivo), empregamos aqui com muito mais propriedade um enfoque sincrônico, onde os hibridismos religiosos são refletidos a partir de conexões, embates e mesclas socioculturais em um dado momento histórico.

\section{O conto de Völsi}

A narrativa de Völsi é encontrada inserida na Oláfs saga hins helga, e denominada de Völsa páttr (o conto de Völsi), preservado no manuscrito Flateyjabók, datado do século XIV. ${ }^{2}$ Basicamente, o relato descreve uma fazenda ao norte da Noruega, onde vivia uma família de nórdicos pagãos. Durante o final de outubro, no momento que morre o cavalo do fazendeiro, este foi utilizado como alimento. Logo após, um escravo corta o pênis do cavalo (víngul) e o filho do senhor o leva para sua mãe e irmã, que o secam com muito cuidado e o envolvem em um pano de linho juntamente com alho poró e outras ervas. Toda noite os moradores da casa realizavam uma oração ao pênis, que era repassado para cada indivíduo após pronunciar uma estrofe. O rei Ólaf o santo estava visitando aquela região no ano de 1029, com dois homens de confiança, e entram na fazenda durante a noite. Após sentarem-se em um banco, observam a entrada da filha do fazendeiro. Saudados, todos os três homens identificam-se pelo nome de Grim (mascarado). Logo após entra o senhor, o seu filho e o escravo, e a mesa de jantar é preparada. Em seguida, o pênis embalsamado (Völsi) é repassado para cada membro da casa pela mulher, primeiro para o seu marido, em seguida para o filho, a filha, o escravo e a escrava, que recitam uma estrofe cada um. Quando o pênis é passado para o rei, este o atira para o cachorro da casa, que imediatamente o devora. Olaf retira sua capa, revelando sua identidade e convertendo todos para o cristianismo.

${ }^{2}$ O Flateyjabók (livro de Flatey) é um manuscrito escrito pelos padres John Pórðarson e Magnus Porhalsson entre 1387-1390. Consiste em 225 grandes fólios, agora reunidos em dois volumes, contendo grande coleção de sagas islandesas (HOLMAN, 2003, p. 96). 

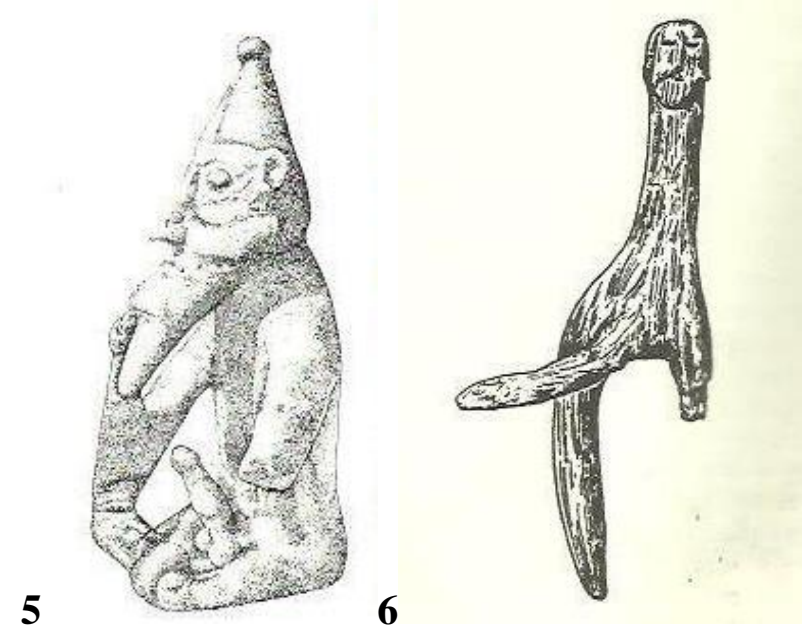

Figura 5: Estatueta de Freyr, Rällinge, Suécia, ano mil. Fonte: GRAHAMCAMPBELL, 2001, p. 182. Nesta representação, podemos perceber a entidade segurando a sua barba, considerada também um símbolo de virilidade entre os povos nórdicos, além do pênis ereto, um atributo comentado na descrição de Adm de Bremen sobre uma estátua deste deus em Uppsala, Suécia.

Figura 6: Estatueta de madeira de Broddenbjerg, Jutlândia, Dinamarca, Idade do Ferro. Fonte: DAVIDSON, 1988, p. 15. Este objeto comprova a existência de simbolismos religiosos relacionados ao falicismo nórdico bem antes da Era Viking.

Essa pequena narrativa sempre foi muito polêmica nos estudos escandinavos. A grande maioria dos pesquisadores inclinou-se a identificar nela a preservação literária de um ancestral rito dos tempos pré-cristãos. Turville-Petre associou a narrativa com o culto do deus Freyr, enquanto Folke Ström relacionou a mesma com a deusa Skadi e as divindades da fertilidade (SIMEK, 2007, p. 365). O mitólogo francês Régis Boyer acredita que Völsi representava um rito sacrificial mágico da Era Viking (BOYER, 1986, p. 155), enquanto Gro Steinsland considera uma referência a um culto para gigantas (Steinsland, 1986, p. 216), idéia compartilhada por BERNÁRDEZ, 2010, p. 186. Neste caminho, baseando-se nas perspectivas dos estudos de cultura material de Neil Price, cogitou-se a narrativa como uma demonstração na crença do falo enquanto símbolo de valores hierárquicos sociais, políticos e religiosos (HEDEAGER, 2011, p. 104-114). Quanto aos críticos, temos K. Düwel na década de 1970, que considerava este conto uma invenção cristã do século XIV para desmoralizar o paganismo (SIMEK, 2007, p. 366). Mais recentemente, em um denso estudo bibliográfico e documental, voltou-se a cogitar a Völsa páttr como um produto mais próximo da época de composição do Flateyjabók que a do paganismo (TOLLEY, 2009, p. 1-18), ou seja, um 
produto literário da Idade Média Tardia. Num caminho intermediário, cogitou-se que os fazendeiros relatados pela saga não eram mais pagãos, mas "tradicionalistas passivos", isto é, cristãos que perpetuavam práticas dos tempos pagãos através do folclore (DUBOIS, 2006, p. 76).

De qualquer maneira, mesmo que o conto seja uma invenção cristã tardia, ele foi baseado essencialmente em uma tradição folclórica que remete a crenças dos tempos pagãos, ainda conhecidas pela audiência da saga no momento em que foi composta uma ideia que mesmo os pesquisadores céticos mais recentes vêm admitindo (TOLLEY, 2009, p. 14; MITCHELL, 2011, p. 56). Procuraremos analisar alguns pontos do conto, confirmando ou questionando alguns referenciais da historiografia, mas essencialmente procurando articular como eles podem servir para o estudo da religiosidade da Escandinávia na Era Viking e nos primeiros tempos do cristianismo.

O primeiro elemento a ser considerado é a estrutura do objeto. O pênis mumificado do cavalo, denominado de Völsi, foi envolto em linho e coberto com alho poró ("líni gaeddr en laukum studdr", Völsavísur 4). O linho (Linum usitatissimum) é uma planta herbácea utilizada tradicionalmente para fabricação de fibras têxteis na Escandinávia desde a pré-história, especialmente no leste da Suécia, e também era um símbolo de riqueza (DAVIDSON, 1998, p. 98-99). O alho-poró (Allium porrum) é uma planta europeia muito utilizada na alimentação, mas ao mesmo tempo, é um das ervas mais associadas à tradição fálica e sexual no mundo germânico, utilizada em encantos para amuletos desde a Antiguidade (MACLEOD, 2006, p. 103). A poesia éddica emprega esta erva como metáfora para a virilidade, a exemplo do herói Sigurd que é comparado a um alho poró crescendo acima da grama ("sem vari graenn laukr", Guðrúnarkviða in forna 2).

Estas duas plantas aparecem inseridas na inscrição rúnica de uma faca de Fløksand, Noruega, datada do século IV d.C e encontrada numa sepultura feminina: "Lina, laukaz, fehu” (Linho, alho poró, prosperidade) (MACLEOD, 2006, p. 103). Evidentemente aqui temos uma fórmula mágica intentando a abundância de comida, protegendo assim toda a fazenda. Essa conexão de fertilidade ctônica tem sentido com outras referências éddicas desta erva, como no momento após a criação de Midgard por Odin, Vili e Ve, onde "brotaram do chão verdejantes alhos porós" ("pá var grund gróin grcenum lauki”, Völuspá 4). 
Em algumas inscrições rúnicas, o nome da erva é abreviado para vários $l$, como na inscrição de Gjersvik, Noruega, e em vários amuletos surge também a runa $n$, Ing, o nome de uma antiga divindade da fertilidade, associada a Freyr nas fontes nórdicas. Cavalos e reis relacionam-se a este deus, e aqui, obviamente, nos remetemos novamente ao exemplo de Völsi. Não somente a carne dos cavalos era consumida em rituais, mas o próprio rei era conectado à fertilidade de todo o reino, sacrificado em tempos de fome (como Domaldi na Ynglinga saga 15). Também encontramos uma conexão entre cavalos, fertilidade, soberania e reis em comum com outras antigas tradições europeias. A maior similitude ritualística entre o mundo nórdico representado por Völsi é com o culto de Reitia, no norte da Itália, cujo santuário tinha cabeças de cavalo e era alcunhada de Pora (alho poró), enquanto sua equivalente romana, a deusa da magia Carmentis, recebia o título de Porrima (MACLEOD, 2006, p. 104-105, 107-108).

Mas se neste contexto mediterrânico a fertilidade é representada por deusas, na área escandinava ela é eminentemente relacionada com a virilidade masculina. Em pinturas rupestres da idade do bronze (especialmente Buhuslan, Suécia), imagens masculinas fálicas surgem em diversos contextos: sagrando a união entre um homem e mulher, segurando armas, remando, etc. Monumentos pétreos imitando pênis são conhecidos na região de Vestlandet, Trondelag e Helgeland (Noruega), e são associadas a regiões sagradas de culto (hov) (HEDEAGER, 2011, p. 112). A maioria das estelas gotlandesas da Era Viking (com caráter funerário) possuem um formato nitidamente fálico. Duas das mais famosas destas estelas, Tjängvide I e Ardre VIII, representam um cavaleiro (Odin ou um herói falecido) entrando no Valhala com o pênis ereto, sendo recebidos por uma valquíria e seu hidromel.

Assim, fertilidade a abundância foram simbolizadas pelo membro masculino ereto. Na célebre descrição de Adam de Bremen, existia uma estátua do deus Freyr em Uppsala com um imenso falo (“cum ingenti priapo”, Gesta Hammaburgensis 26), do mesmo modo que a estatueta sueca de Rällinge, século XI, considerada uma representação deste deus com membro enrijecido. ${ }^{3} \mathrm{O}$ falo não é meramente uma

\footnotetext{
${ }^{3}$ Pesquisadores estão contestando a interpretação de que esta estatueta seja de Freyer (SANMARK, 2004, p. 160; TOLLEY, 2009, p. 15). Neil Price afirma que ela pode se tratar tanto da representação de Freyr como de Odin, Loki, um anão, um gigante, um rei, um homem - ou seja, qualquer figura masculina libidinosa apontada pelas fontes nórdicas (PRICE, 2006, p. 179-180). Questionamos esse ponto de vista: Odin geralmente é representado como um caolho nas esculturas e pingentes; a única evidência concreta de uma imagem de Loki é a pedra de Snaptun (um homem de bigode com a boca costurada). Se
} 
metáfora para os cultos de fertilidade, mas um símbolo do poder de penetração, ocupando aqui um código social de dominação e submissão relacionado com as diferenças de hierarquia social e sexual. Deste modo, a sexualidade não é uma esfera separada da política no mundo nórdico, atuando no cotidiano religioso e social (HEDEAGER, 2011, p. 115, 118).

O segundo aspecto a ser considerado no conto de Völsi é o ritual. No momento em que todos recebem o Völsi e recitam poemas, uma das estrofes repete-se por nove vezes: "Receba mörnir este objeto sagrado" ("Diggi mörnir petta blaeti”, Völsavísur 4). A tradução da palavra mörnir é muito debatida, recebendo duas conotações: espada, num sentido similar a pênis (nos poemas mnemônicos pulur); e giganta (como no poema éddico Haustlöng 6, refererindo-se a Skaði e no poema escáldico pórsdrápa 7 relacionada a seres combatidos pelo deus Thor). Dentro deste último referencial, a pesquisadora Gro Steinsland intentou perceber no conto de Völsi a prova de um antigo culto para gigantas, onde o pênis do cavalo representa o deus Freyr e mörnir uma giganta (STEINSLAND, 1986, p. 216-222). Concordamos com a pesquisadora quando concebe as gigantas como integrantes de uma cosmovisão nórdica (portanto mítica), onde esses seres femininos foram considerados muito importantes, tanto como mantenedores do casamento quanto da ordem e do caos no universo, como os deuses. Mas aqui temos que separar mito de rito, algo que já debatemos no início deste artigo. Reiteramos Tolley (2009, p. 17) e Dumézil (1992, p. 112-113) de que não existiu no mundo nórdico uma veneração a gigantas e também baseado em pesquisas toponômicas, o acadêmico Brink (2007, p. 125) cita que únicos seres femininos que receberam culto na Era Viking foram as deusas Freyja e Frigg.

As figuras de Gerd e Skadi constituíram importantes elementos nos simbolismos hierogâmicos, onde a figura de um deus casando com uma giganta foi um elemento central nos rituais de fertilidade. Pequenas placas de ouro descobertas na Escandinávia e retratando um homem abraçando uma mulher, vem sido considerados oferendas votivas simbolizando Freyr e Gerd - como o local do achado originalmente era o salão real, esse casamento pode ter sido conectado a uma origem mítica da dinastia real

considerarmos que outras estatuetas (como a do deus Thor de Eyrarland, Islândia) possuem exatamente a mesma dimensão (6,9 centímetros), indubitavelmente trata-se de amuletos relacionados às principais divindades. E levando em conta o relato de Adam de Bremen, a maior probabilidade é de que a estatueta seja mesmo a representação de Freyr. 
(SØRENSEN, 1999, p. 215). Mas isso não significa que a giganta (no caso, Gerd) foi cultuada, e sim, de que ela era parte importante de um ritual que na realidade, prepondera a importância de uma divindade masculina, o deus Freyr. Do mesmo modo, o conto de Völsi enfatiza a conservação e celebração de um pênis de cavalo, que deve ter representado originalmente um vínculo direto com este deus. Neste caso, a frase “Receba mörnir este objeto sagrado”, somente reforça uma sacralidade relacionada ao membro animal. A tradição falocêntrica de um amor mágico pode ser conferida em outras fontes nórdicas durante o medievo, como na inscrição rúnica de Bergen (século XIII) e no poema Buslubaen ${ }^{4}$ e também está conectada a um imaginário onde o pênis de cavalo desempenha um papel central tanto na difamação pública quanto no conceito de masculinidade escandinava (MITCHELL, 2011, p. 57).

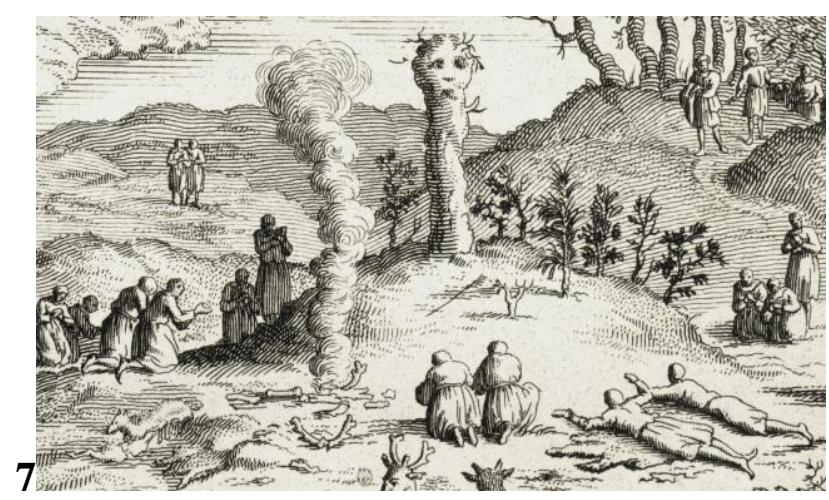

Figura 7: Ilustração de culto lapão para a deusa Wirku Accha (acima de montículo funerário), de autoria de Bernard Picart, realizada entre 1600 e 1700 e publicada na edição francesa do livro The ceremonies and religious customs of the various nations, em 1725. Fonte: http://www.flickr.com/photos/28772513@N07/3710997426/ A imagem alude a cultos pagãos relacionados a sexualidade e fertilidade da terra, ainda realizados no extremo norte da Escandinávia durante o século XVII. Os lapões do norte da Suécia e Noruega mantiveram conexões e influências com a religiosidade nórdica da Era Viking, que vem sendo apontada por vários pesquisadores recentes, especialmente a construção de plataformas, postes, estátuas de pedra e madeira, altares e sítios sacrificiais e de adoração (SANMARK, 2004, p. 169-176; DUBOIS, 1999, p. 12-17).

O último elemento a ser considerado no conto de Völsi são as pessoas envolvidas. A mulher do fazendeiro ocupa um lugar central, enfatizado pelos pesquisadores como um reflexo da importância feminina nos cultos domésticos, equivalente a uma sacerdotisa (BERNÁRDEZ, 2010, p. 184). Esse papel feminino preponderante seria um reflexo do culto às gigantas (STEINSLAND, 1986, p. 216-218) ou da oposição do

\footnotetext{
${ }^{4}$ Para uma análise da relação entre falicentrismo e gigantas no poema Buslubaen, consultar: LANGER, 2009b, p. 66-90.
} 
poder feminino na esfera privada, oposto ao poder masculino da esfera pública (ritos odínicos) (BOROWSKY, 1999, p. 25). Esta última pesquisadora ainda compara os rituais de $s e i d r^{5}$ e as perfomances femininas pagãs (como a da poetisa Steinunn ${ }^{6}$ ) com o controle da fazendeira com o Völsi, e do mesmo modo que Steinsland opõe esse ritual doméstico com a esfera dos cultos a Odin, representado pelos guerreiros e elite aristocrática. Nas concepções destas duas pesquisadoras, temos evidentemente um referencial feminista, que consideramos um tanto anacrônico.

Tabela 1: Esquema diacrônico da narrativa de Völsi (para a região da Escandinávia)

\begin{tabular}{|c|c|c|}
\hline $\begin{array}{l}\text { Era Viking (793-1066) } \\
\text { Origem do ritual }\end{array}$ & $\begin{array}{l}\text { Período cristão inicial } \\
\text { (século XI-XII) } \\
\text { Composição oral do conto }\end{array}$ & $\begin{array}{l}\text { Período cristão tardio } \\
\text { (século } \mathbf{X V}) \\
\text { Forma literária definitiva } \\
\text { do conto }\end{array}$ \\
\hline $\begin{array}{l}\text { Ritual } \\
\text { desconhecido, envolvendo } \\
\text { o simbolismo da união } \\
\text { entre um deus e uma } \\
\text { giganta, possivelmente } \\
\text { conectado à figura do } \\
\text { cavalo, à plantas (linho, } \\
\text { alho poró) e ao deus Freyr. }\end{array}$ & $\begin{array}{l}\text { Ritual hierogâmico } \\
\text { empregado durante } \\
\text { cerimônias de casamento e } \\
\text { colheitas no mundo rural, } \\
\text { de origem pagã e } \\
\text { preservado pelo folclore. } \\
\text { Irreverente e humorado, } \\
\text { essencialmente empregado } \\
\text { para fecundar } \\
\text { simbolicamente a noiva. }\end{array}$ & $\begin{array}{l}\text { Celebração de um pênis de } \\
\text { cavalo em todas as noites } \\
\text { durante o Outono, pelos } \\
\text { membros de uma fazenda. } \\
\text { O objeto é destruído pelo } \\
\text { rei cristão Oláf. A intenção } \\
\text { objetiva do conto é } \\
\text { desmoralizar o paganismo, } \\
\text { mas empregando uma } \\
\text { antiga narrativa conhecida } \\
\text { da audiência. }\end{array}$ \\
\hline
\end{tabular}

Em primeiro lugar, não há como relacionar diretamente os rituais de seidr ao conto de Völsi: ${ }^{7}$ a maioria das fontes literárias, inclusive a que contém mais detalhes, a Eiríks saga rauða ${ }^{8}$, não ocorre qualquer menção a falo ou cavalos. Em segundo, apesar de não sermos contrários a ideia da importância do papel feminino na esfera doméstica e na religiosidade ${ }^{9}$ e das gigantas na mitologia nórdica em geral, e mais especificamente nas concepções hierogâmicas, não há como negar a preponderância de um pênis de cavalo na narrativa - um detalhe omitido por Borowsky em toda a sua argumentação. A

\footnotetext{
${ }^{5} \mathrm{O}$ seidr era um ritual da Era Viking essencialmente feminino e praticado tanto para fins curativos, quanto amorosos, maléficos e para auxílio em época de escassez (LANGER, 2010, pp. 177-202).

${ }^{6}$ A respeito da performance pagã de Steinunn na Njáls saga, consultar LANGER, 2011, pp. 3-22.

7 A não ser o fato que o termo Völsi pode ser relacionado a volr (bastão), utilizado pelas volvas e praticantes de seidr (HEDEAGER, 2011, p. 107).

${ }^{8}$ Para detalhes sobre o episódio de seidr nesta fonte, consultar: LANGER, 2010, pp. 177-202.

9 Concordamos com Borowsky (1999, p. 32) quando afirma que as performances femininas eram importantes em situações de crise para manter o equilíbrio entre a fazenda e a esfera pública; e com Jochens (1998, p. 163) que considera que o cristianismo colaborou para declinar a importância do papel feminino do período pagão.
} 
essência da narrativa é a de um culto falocêntrico e não de um ritual a um ser feminino. Mesmo no mundo rural nórdico, onde as narrativas orais de fertilidade eram essenciais para a sobrevivência cotidiana (especialmente nas colheitas), os deuses ocupam um lugar privilegiado. Não há uma separação tão nítida entre o espaço da lavoura, da criação dos animais ou do ambiente doméstico. Todos são conectados e cada deus ou deusa ocupa um lugar dependendo da situação e não do contexto espacial. Assim, deuses são relacionados a organização das comunidades, a guerra, ao trabalho, ao campo e terra, as viagens, negócios e heranças, leis, enquanto que as deusas se concentram em aspectos particulares da vida (nascimento, crescimento, cura, amor, sexo). De maneira nenhuma as deusas eram concebidas como "campeãs" e defensoras das mulheres oprimidas em um mundo masculinista (DAVIDSON, 1998, p. 189-190).

Em terceiro lugar, essa oposição entre um culto odínico de caráter masculinista, ligado à realeza e aos guerreiros (supostamente representando pelo mesmo nome dos três visitantes na narrativa, Grim, mascarado), versus um culto a fertilidade feminino e doméstico (representado pela mulher do fazendeiro) também é mais um referencial anacrônico, portanto, contemporâneo. ${ }^{10}$ Como já vimos antes, diversos aspectos dos rituais de fertilidade envolviam aspectos masculinos como femininos. Se por um lado, tanto Freyr quanto Njord podem encarnar simbolismos propiciatórios, paz e casamentos, também Thor é uma importante deidade masculina que protege a vida na terra para quem depende da caça, pesca e fazenda. ${ }^{11}$ Mesmo entidades tipicamente femininas, como as dísir, tanto encarnam a fertilidade da terra quanto possuem conexão com casas reais (DAVIDSON, 2001, p. 101-106, 113). ${ }^{12}$ Numa fazenda, tanto o fazendeiro como a sua esposa podiam conduzir ou liderar os cultos religiosos (ROESDAHL \& SØRENSEN, 2008, p. 130), não havendo necessariamente uma especialidade de gênero neste quesito. Neste sentido, concordamos com Tooley (2009, p. 17) quando afirma que apesar do conto basear-se no conhecimento da antiga tradição

${ }^{10}$ Para este referencial na narrativa de Völsi consultar especialmente: BERNÁRDEZ, 2010, p. 185; BOROWSKY, 1999, p. 24-25.

${ }^{11}$ Thor é conectado diretamente com a fertilidade da terra (ROESDAHL \& SØRENSEN, 2008, p. 130).

12 Também deidades masculinas relacionadas com o sexo e a fertilidade possuíam conexões com a soberania e a liderança aristocrática, como Freyr. "No contexto nórdico, Odin é associado com o alto escalão de poder, com reis e nobres; Freyr e Thor são deuses do nível da chefia local (...) Tanto Thor quanto Freyr representam a fertilidade para as chefias locais". Mas também temos que estar atentos às variações regionais dos cultos: enquanto Odin é preponderante na alta aristocracia do oeste nórdico, Freyr e Thor são mais importantes no mundo islandês (STEINSLAND, 2001, p. 38, 39). 
nórdica de mulheres liderando cultos e práticas religiosas, foi elaborado dentro do referencial cristão de que a autoridade feminina é diabólica.

Como conclusão, podemos apontar alguns caminhos para futuros debates, persistindo no referencial de que existem ainda muitas possibilidade reflexivas para se pensar as fontes medievais. A ideia de que o conto de Völsi é um produto tardio do cristianismo pode ser questionada em um dado omitido pelos pesquisadores céticos (como TOOLEY, 2009). Nas ilhas Féroe (de colonização norueguesa), foi preservado um folclore relacionado ao casamento, denominado Drunnur. Um osso do rabo de um boi ou ovelha decorado com fitas é passado durante esta cerimônia, momento no qual o participante deve proferir um verso pequeno antes de passar para a próxima "vítima". Geralmente os versos possuem insinuações de jocosidades sexuais (DUBOIS, 2006, p. 76). O detalhe de um membro animal com fitas sendo passado para outra pessoa após uma versificação é estruturalmente idêntico à narrativa de Völsi. Com isso, os detalhes do humor (especialmente as estrofes do irmão passando o objeto para a irmã e a dos escravos, Völsavísur 6 e 9), não se devem a um referencial do cristianismo debochando do paganismo, mas de uma característica própria do humor sexual da Era Viking, que pode ser observado em outras fontes literárias mais antigas, como nas cenas de casamento da porgils saga ok Halfliða 10. Práticas similares também podem ser conferidas em outras fontes folclóricas da Europa Setentrional, como festas das colheitas da Escócia e Bavária (DAVIDSON, 2001, p. 105).

Existe uma grande probabilidade de que o conto de Völsi seja um eco de ritos hierogâmicos efetuados ainda na Era Viking, mas que desconhecemos maiores detalhes (ver tabela 1). Essas crenças sobreviveram pelo folclore da Idade Média Central, associadas a casamentos e festas das colheitas, mas já numa sociedade cristianizada. Com o tempo, a literatura do medievo tardio transformou-se num instrumento eficaz de conversão, adaptando a narrativa para um efetivo controle ideológico da audiência. As antigas crenças pagãs são agora desmoralizadas pela figura triunfante do santo, que substitui a adoração de objetos idólatras pela salvação cristã, mas que ainda persistem na memória coletiva. Com isso a literatura ao mesmo tempo em que é produto da história, também é agente transformadora dela. Mas de qualquer modo, é um reflexo do dinamismo cultural em que a religiosidade está inserida. 
Agradecimento: para a professora Ms. Luciana de Campos (NEVE) pela revisão no presente texto.

Referenciais

Fontes primárias:

ANÔNIMO, Guðrúnarkviða in forna, séc. XII. Texto em nórdico antigo, edição de Sophus Bugge's. Disponível em: http://etext.old.no/Bugge/gudrun2.html Acesso em 13 de maio de 2012.

ANÔNIMO, Völsa páttr, séc. XV. Texto em nórdico antigo, edição de Guðni Jónsson, disponível em: http://www.heimskringla.no/wiki/Völsa_páttr Acesso em 05 de janeiro de 2011.

ANÔNIMO, Völuspá, séc. X. Texto em nórdico antigo, edição de Guðni Jónsson, disponível em: http://www.heimskringla.no/wiki/Völuspá Acesso em 24 de abril de 2002.

BREMEN, Adam de. Gesta Hammaburgensis ecclesiae pontificum, 1076. Texto em latim, disponível em: http://hbar.phys.msu.su/gorm/chrons/bremen.htm Acesso em 23 de maio de 2012.

\section{Fontes secundárias:}

BARLETT, Robert. From paganism to Christianity in medieval Europe. In: BEREND, Nora (ed.). Christianization and the rise of Christian monarchy. Cambridge: Cambridge University Press, 2007, pp. 47-72.

BELLOTTI, Karina Kosicki. Mídia, religião e história cultural. Rever: Revista de Estudos da Religião n. 4, 2004, pp. 96-115.

BERNÁRDEZ, Enrique. La historia de Völsi. Los mitos germánicos. Madrid: Alianza Editorial, 2010, pp. 179-185.

BOROWSKY, Zoe. Never in public: women and performance in Old Norse literature. Journal of American folklore 112 (443), 1999, pp. 6-39.

BOYER, Régis. Héros et dieux du Nord: guide iconographique. Paris: Flammarion, 1997.

BOYER, Régis. La grande déesse du Nord. Paris: Berg International, 1995. 
BOYER, Régis. Le monde du double: la magie chez les anciens scandinaves. Paris: Berg Ingernational, 1986.

BOYER, Régis. La religion des anciens scandinaves. Paris: Payot, 1981.

BRINK, Stefan. How uniform was the old norse religion? In: QUINN, Judy (Ed.). Learning and understanding in the Old Norse world: essays in honour of Margaret Clunies Ross. London: Brepols, 2007, pp. 105-136.

CARDOSO, Ciro. História das religiões. Um historiador fala de teoria e metodologia. Bauru: Edusc, 2005, pp. 209-230.

CUCHE, Denys. A noção de cultura nas ciências sociais. SP: Edusc, 2002.

DAVIDSON, Hilda Ellis. The lost beliefs of Northern Europe. London: Routledge, 2001.

DAVIDSON, Hilda Ellis. Roles of the northern goddess. London: Routledge, 1998.

DAVIDSON, Hilda Ellis. Myths and symbols in Pagan Europe: early Scandinavian and celtic religions. New York; Syracuse University Press, 1988.

DETIENNE, Marcel. A invenção da mitologia. Brasília: UNB, 1992.

DUBOIS, Thomas. Rituals, witnesses, and sagas (Völsa páttr). In: ANDRÉN, Anders, JENNBERT, Kristina \& RAUDVERE, Catharina. (Eds.). Old Norse religion in longterm perspectives: origins, changes and interactions. Lund: Nordic Academic Press, 2006, pp. 76-77.

DUBOIS, Thomas. Nordic religions in the Viking Age. Philadelphia: University of Pennsylvania Press, 1999.

DUMÉZIL, Georges. Do mito ao romance. São Paulo: Martins Fontes, 1992.

FRANCO JÚNIOR, Hilário. A Eva barbada: ensaios de mitologia medieval. SP: Edusp, 1996.

GUERRIERO, Silas. A magia existe? SP: Paulus, 2003.

GINZBURG, Carlo. História noturna: decifrando o sabá. SP: Cia das Letras, 2001. GRAHAM-CAMPBELL, James. The Viking World. London: Frances Lincoln, 2001. HEDEAGER, Lotte. Phallus, fertility and death. Iron Age myth and materiality: an archaeology of Scandinavia AD 400-1000. London: Routledge, 2011, pp. 104-114. HERMANN, Jaqueline. História das religiões e religiosidades. In: CARDOSO, Ciro \& VAINFAS, Ronaldo. (org). Domínios da história. RJ: Campus, 2010, pp. 315-336. 
HOLMAN, Katherine. Historical dictionary of the Vikings. Oxford: The Scarecrow Press, 2003.

JOCHENS, Jenny. Women in Old Norse Society. Ithaca: Cornell University Press, 1998.

LANGER, Johnni. A morte de Odin? Representações do Ragnarök na arte das ilhas britânicas (séc. X). Medievalista 11, 2012, pp. 1-30. Disponível em: <http://ufma.academia.edu/JohnniLanger/Papers> Acesso em 05/01/2012.

LANGER, Johnni. Pagãos e cristãos na Escandinávia da Era Viking: reflexões sobre o episódio de conversão da Njals saga. Revista Brasileira de História das Religiões 4(10) 2011a, pp. 3-22. Disponível em: <http://ufma.academia.edu/JohnniLanger/Papers> Acesso em 05/01/2012.

LANGER, Johnni. Símbolos religiosos dos vikings. História, imagem e narrativas 11, 2011b, pp. 1-28. Disponível em: <http://ufma.academia.edu/JohnniLanger/Papers> Acesso em 05/01/2012.

LANGER, Johnni. Seiðr e magia na Escandinávia Medieval: reflexões sobre o episódio de Porbjörg na Eiríks saga rauða. Revista Signum 11(1), 2010, pp. 177-202. Disponível em: 〈http://ufma.academia.edu/JohnniLanger/Papers> Acesso em 05/01/2012.

LANGER, Johnni. Galdr e feitiçaria nas sagas islandesas: uma análise do poema Buslubæn. Brathair 9(1) 2009a, pp. 66-90. Disponível em: <http://ufma.academia.edu/JohnniLanger/Papers> Acesso em 05/01/2012.

LANGER, Johnni. Deuses, monstros, heróis: ensaios de mitologia e religião viking. Brasília: Editora da UNB, 2009b.

LANGER, Johnni. Religião e magia entre os vikings. Brathair 5(2), 2005, pp. 55-82.

Disponível em: <http://ufma.academia.edu/JohnniLanger/Papers> Acesso em 05/01/2012.

LANGER, Johnni. Morte, sacrifício humano e renascimento: uma interpretação iconográfica da estela viking de Hammar I. Mirabilia 3, 2003. Disponível em: <http://ufma.academia.edu/JohnniLanger/Papers> Acesso em 05/01/2012.

LAPLANTINE, François. Aprender antropologia. SP: Brasiliense, 1999.

LERATE, Luis. Estrofas de Volsi. Poesía antiguo-nórdica. Madrid: Alianza Editorial, 1993, pp. 59-63.

MACLEOD, Mindy \& MEES, Bernard. Runic amulets and magic objects. New York: The Boydell Press, 2006. 
MASSENZIO, Marcello. A história das religiões na cultura moderna. SP: Hedra, 2005 .

MITCHELL, Stephen A. Witchcraft and magic in the Nordic Middle Ages. Philadelphia: University of Pennsylvania Press, 2011.

MITCHELL, Stephen A. Odin, magic, and a Swedish trial from 1484. Scandinavian Studies 81, 2009, pp. 263-286.

MONTEIRO, Paula. Magia e pensamento mágico. SP: Ática, 1986.

PRICE, Neil. What's in a name? An archaeological identity crisis for the Norse gods (and some of their friends). In: ANDRÉN, Anders, JENNBERT, Kristina \& RAUDVERE, Catharina. (Eds.). Old Norse religion in long-term perspectives: origins, changes and interactions. Lund: Nordic Academic Press, 2006, pp. 177-182.

RAUDVERE, Catharina. Popular religion in the Viking Age. In: BRINK, Stefan (orgs.). The viking world. London: Routledge, 2012, pp. 235-243.

ROESDAHL, Else \& SØRENSEN, Preben Meulegracht. Viking culture. In: HELLE, Knut. Cambridge History of Scandinavia, vol. 1, Prehistory to 1520. Cambridge: Cambridge University Press, 2008, pp. 121-147.

SANCHIS, Pierre. No mapa das religiões, há lugar para a "religiosidade"? Revista de Ciências Humanas 30, UFSC, 2001, pp. 183-198.

SANMARK, Alexandra. The nature of Pre-Christian religious custom. In: Power and conversion: a comparative study of Christianization in Scandinavia. Occasional Papers in Archaeology 34, 2004, pp. 147-185.

SIMEK, Rudolf. Völsi. Dictionary of Northern Mythology. Cambridge: D.S. Brewer, 2007, pp. 365-366.

SØRENSEN, Preben Meulengracht. Religion Old and New. In: SAWYER, Peter (Ed.). The Oxford Illustrated history of the Vikings. Oxford: Oxford University Press, 1999, pp. 202-224.

STEINSLAND, Gro. Origin myths and rulership. From the Viking Age ruler to the ruler of medieval historiography: continuity, transformations and innovations. In: STEINSLAND, Gro; SIGURĐSSØN, Jón Viðar; REKDAL, Jan Erik (eds.). Ideology and power in the Viking and Middle Ages: Scandinavia, Iceland, Ireland, Orkney and the Faroes. Leiden: Brill, 2011, pp. 15-68. 
STEINSLAND, Gro. Giants as recipients of cult in the Viking Age? In: STEINSLAND, Gro (Ed.). Words and objects: towards a dialogue between archaeology and history of religion. Oslo: Norwegian University Press, 1986, pp. 212-222.

THOMAS, Keith. Religião e o declínio da magia. SP: Cia das Letras, 1991.

TITIEV, Mischa. Introdução á Antropologia cultural. Lisboa: Fundação Calouste Gulbekian, 1979.

TOLLEY, Clive. Völsa páttr: pagan lore or Christian lie? Analecta Septentrionalia:

Papers on the history of North Germanic Culture and literature. Berlin: Walter Gruyter, 2009, pp. 1-21.

Recebido: 03/10/2013

Received: $10 / 03 / 2013$

Aprovado: 19/12/2013

Approved: 12/19/2013 